\title{
Relationship Between Cough Reflex Sensitivity and Body Mass Index in Children With Chronic Cough - a Pilot Study
}

\author{
Renata PECOVA ${ }^{1}$, Jan SOJAK ${ }^{1,2}$, Peter DURDIK ${ }^{3}$, Tomas ZATKO ${ }^{1}$, Eva OMAR \\ MOHAMEDOVA ${ }^{4}$, Marian GRENDAR ${ }^{5}$, Milos TATAR ${ }^{1}$
}

${ }^{1}$ Department of Pathological Physiology, Jessenius Faculty of Medicine in Martin, Comenius University in Bratislava, Martin, Slovak Republic, ${ }^{2}$ Clinic of Otorhinolaryngology and Head and Neck Surgery, Faculty of Medicine, Slovak Medical University in Bratislava, Central Military Hospital in Ruzomberok, Slovak Republic, ${ }^{3}$ Clinic of Children and Adolescent, Jessenius Faculty of Medicine in Martin, Comenius University in Bratislava, University Hospital Martin, Martin, Slovak Republic, ${ }^{4}$ Outpatient Department of Clinical Immunology and Allergology in Ruzomberok, Slovak Republic, ${ }^{5}$ Biomedical Center, Jessenius Faculty of Medicine in Martin, Comenius University in Bratislava, Martin, Slovak Republic

Received March 30, 2020

Accepted October 6, 2020

\section{Summary}

Obesity is characterized by chronic, low-grade systemic inflammation. Obesity may also be associated with chronic cough. The aim of this pilot study was to clarify relation of cough reflex sensitivity and body mass index (BMI) in children with chronic cough. Altogether 41 children having symptoms of chronic cough were submitted to cough reflex sensitivity measurement. We assessed the relation of cough reflex sensitivity (CKR) due to BMI. Cough reflex sensitivity was defined as the lowest capsaicin concentration which evoked two (C2) or five (C5) coughs. Capsaicin aerosol in doubling concentrations (from 0.61 to $1250 \mu \mathrm{mol} / \mathrm{l}$ ) was inhaled by a single breath method (KoKo DigiDoser; nSpire heath Inc, Louisville, CO, USA), modified by the addition of an inspiratory flow regulator valve (RIFR; nSpire heath Inc, Louisville, CO, USA). BMI was calculated. Pulmonary function was within normal range. Concentrations of capsaicin causing two (C2) and five coughs (C5) were reported. Children' (22 boys and 19 girls, mean age 6.8 years) cough reflex sensitivity (median, with the InterQuartile Range) for C2 was 19.5 (73.4) $\mu \mathrm{mol} / \mathrm{l}$; for C5 it was 78.1 (605.5) $\mu \mathrm{mol} / \mathrm{l}$. We have noticed statistically significant relation of the cough reflex sensitivity (C5) and body mass index $(P<0.0001)$; however, the effect size was small, $R^{2}=0.03$. Increase of body mass index in one unit is associated with $-34.959 \mu \mathrm{mol} / \mathrm{l}$ decrease of $\mathrm{C} 5$. We did not find a statistically significant relation between $\mathrm{C} 2$ and $\mathrm{BMI}(\mathrm{P}=0.41)$. The median value of CKR (C2) in boys is not statistically significantly different than the median value of CKR (C2) in girls (P-value 0.5). The median value of CKR (C5) in boys is not statistically significantly different than the median value of CKR (C5) in girls (P-value 0.5). Increase of body mass index in children suffering from chronic cough relates to decrease of cough reflex sensitivity (C5 value).

\section{Key words}

Cough • Chronic cough • Cough reflex sensitivity • Body mass index $\bullet$ Children $\bullet$ Atopy

\section{Corresponding author}

R. Péčová, Department of Pathological Physiology, Jessenius Faculty of Medicine in Martin, Comenius University in Bratislava, Malá Hora 4C, 03601 Martin, Slovak Republic. E-mail: renata.pecova@uniba.sk

\section{Introduction}

Increase in prevalence of obesity has become a worldwide major health problem in adults, as well as among children and adolescents. Overweight and obesity in childhood and adolescence has lately developed into a global health issue (Weihrauch-Blüher et al. 2018). Obesity plays an important role also in the development and progression of respiratory diseases. 
In asthma, obesity is considered a major comorbidity that exacerbates the respiratory symptoms (Porsbjerg and Menzies-Gow 2017). Many epidemiological studies have shown that obese patients have a higher risk of developing asthma than the general population demonstrating that obesity is involved in the development of asthma (Beuther and Sutherland 2007). It is also established that asthma associated with obesity is a phenotype with more difficult-to-treat asthma compared to non-obese subjects (Moore et al. 2010).

Chronic cough is a common entity in respiratory medicine. It is a complex disorder. However, body mass index (BMI) measurement and assessment of obesity markers are not included in the evaluation of patients with chronic cough. Chronic cough places high demands on health care systems but it is not classically associated with obesity (Guilleminault 2019).

With respective prevalence of $13 \%$ and $9.6 \%$, obesity and chronic cough are two common conditions worldwide. The crucial role of obesity has been highlighted in the development and progression of many respiratory diseases. According to the results of epidemiological studies, obesity, particularly abdominal obesity, may also be associated with chronic cough. Chronic cough seems to be more severe in obese patients compared to normal-weight subjects (Guilleminault 2019). It was reported that patients with a higher body mass index (BMI) experience cough more often than other patients and the cough is more severe in obese patients (Moralles-Estrella et al. 2017).

The link between obesity and chronic cough has been suggested in the literature. In the guidelines on chronic cough management, no difference has been highlighted between obese and normal-weight individuals. The beneficial effect of weight loss has been demonstrated in many obesity-related diseases. Weightloss procedures may constitute part of the treatment of chronic cough in obese patients (Guilleminault 2019). The higher BMI is associated with a higher prevalence of symptoms of wheeze and cough in children (Schachter et al. 2003).

The aim was to determine if increased body weight, as measured by body mass index, is associated with a change of cough reflex sensitivity (activity of airway afferent nerve-endings) in children suffering from chronic cough.

\section{Methods}

\section{Selection criteria and subjects}

The inclusion criteria to enter the study were: 1) age from 3 to 15 years, 2) positive anamnesis of chronic cough, cough lasting longer than 4 weeks (Chang et al. 2001, Chang et al. 2017), 3) status without signs of acute airway inflammation and signs of respiratory disorders with exclusion of obstructive ventilatory defect verified by auscultation by pediatrician, spirometry (ZAN500 Body, nSpireHealtGmbh, Germany) and complete ENT (Ear, Nose and Throat) examination nasofiberendoscopy (Karl Storz 11101RP2, Ø2.5 mm, Germany), inspection of oral cavity, oropharynx, otomicroscopy, tympanometry, anterior rhinomanometry, microbial cultivation, 4) good cooperation during the spirometry and cough reflex sensitivity (CRS) examination with relevant outcomes (hyporeactors were excluded), 5) negative anamnesis related to the respiratory and allergic diseases and no mentioned allergy treatment as well; outpatient examination by immunoallergologist - total immunoglobulins E (IgE), specific IgE, pediatric panel for selected inhalation and food allergens, skin prick tests for year-round and seasonal inhalation allergens, 6) the children didn't take any topical and systemic corticosteroids, antihistamines, antileukotrienes and decongestants during the examination and minimally 2 weeks before being examined. All children who met the given criteria underwent body height, weight (digital calibrated weight Seca 61987, Germany) and CRS measurement.

41 children ( 22 boys and 19 girls, age range 4-13 years, mean age 6.8 years) were included into the study. Based on outpatient examination by immunoallergologist patients were divided into subgroups of 17 atopy-negative ( 6 boys, 11 girls, mean age 6.9 years) and 24 atopy-positive patients (16 boys, 8 girls, mean age 6.7 years). As an atopy positive we consider a personal or familial tendency to produce IgE antibodies in response to low doses of allergens, commonly occurring in the environment, usually proteins everyone is exposed to. Second criterion is tendency to develop typical symptoms such as asthma, rhino-conjunctivitis, or eczema/dermatitis. The term atopy was used if an IgE sensitization has been documented by IgE antibodies in serum or by a positive skin prick test (Johansson et al. 2004).

The study was approved by the Ethics Committee of Jessenius Faculty of Medicine in Martin, Comenius University in Bratislava, Slovakia and was 
performed according to the Declaration of Helsinki. Each parent of the observed child was properly informed about the study, about the possibilities of cough treatment and was asked to sign an informed consent.

\section{Spirometry and cough sensitivity testing}

All subjects underwent initial screening of their basic lung functions measured by spirometry before and after capsaicin challenge (KoKo DigiDoser-Spirometer; nSpire health Inc., Louisville, CO, USA) to rule out airway obstruction.

CRS was assessed using capsaicin cough challenge, performed in agreement with the ERS guidelines (Morice et al. 2007) with modification for pediatric use (Varechova et al. 2008) (we used a compressed air-driven nebuliser (model 646; DeVilbiss Health Care, Inc., Somerset, PA, USA) controlled by a dosimeter (KoKo DigiDoser-Spirometer; nSpire health Inc., Louisville, CO, USA) with an inspiratory flow regulator valve added (RIFR; nSpire health Inc., Louisville, CO, USA) to assign identical inspiratory flow rate during capsaicin inhalations in all subjects. Each subject inhaled saline randomly interposed among 12 inhalations of incremental capsaicin aerosol concentrations (0.61-1250 $\mu \mathrm{mol} / \mathrm{l})$. Each administration of saline and capsaicin aerosol was performed at $1 \mathrm{~min}$ intervals with the inhalation time set at $400 \mathrm{~ms}$. The number of coughs within $30 \mathrm{~s}$ after aerosol administration was counted. The end-point of cough challenge was the inhalation of capsaicin concentration that provoked at least 5 coughs (C5) or when the maximum concentration of capsaicin $(1250 \mu \mathrm{mol} / \mathrm{l})$ was achieved. The concentration of capsaicin causing at least two coughs was assigned as $\mathrm{C} 2$ and concentration of capsaicin causing at least 5 coughs was assigned as C5. For children that did no cough at any concentration of capsaicin, CRS value was assigned $1250 \mu \mathrm{mol} / \mathrm{l}$.

The CRS measurement was realized as a singledose capsaicin test. Gradually, with the increasing concentrations of capsaicin we determined sensitivity threshold of the airway nerve endings responsible for coughing.

\section{Body mass index percentile}

BMI can be considered an alternative to direct measures of body fat. In general, BMI is an inexpensive and easy-to-perform method of screening for weight categories that may lead to health problems. After BMI is calculated for children and teens, it is expressed as a percentile which can be obtained from either a graph or a percentile calculator. These percentiles express a child's BMI relative to children in the U.S. who participated in national surveys that were conducted from 1963-1965 to 1988-1994 (Kuczmarski et al. 2002). Because weight and height change during growth and development, as does their relation to body fatness, a child's BMI must be interpreted relative to other children of the same sex and age.

Based on height and weight of patients we calculated BMI, BMI percentile, assigned the weight category (underweight - less than the $5^{\text {th }}$ percentile; normal or healthy weight $-5^{\text {th }}$ percentile to less than the $85^{\text {th }}$ percentile; overweight $-85^{\text {th }}$ to less than the $95^{\text {th }}$ percentile; obese - equal to or greater than the $95^{\text {th }}$ percentile).

Obtained parameters of CRS and BMI were mutually statistically compared and relation between CRS and weight was statistically evaluated. The results were evaluated and interpreted separately for a group of all patients, group of atopy-negative patients and for a group of atopy-positive patients.

\section{Statistical analysis}

Obtained parameters of CKR were mutually statistically compared and relation between CKR in obese and non-obese children, obese and non-obese atopic children was statistically evaluated. The results were evaluated separately for each individual and subsequently for the group as a whole. The results were expressed as median values, the level of statistical significance was determined as $\mathrm{P}<0.05$ and $\mathrm{P}<0.01$. Wilcoxon rank-sum test was used.

The association between CKR and BMI was visualized by a crossplot. Due to the presence of outliers and influential observations in the data, instead of the Ordinary Least Squares method we have used the robust regression ( $\mathrm{M}$ estimator) to fit the regression line into the data. Results with p-value below 0.05 were considered statistically significant. Software used: R Core Team (2015), R: A language and environment for statistical computing ( $\mathrm{R}$ Foundation for Statistical Computing, Vienna, Austria, URL - https://www.R-project.org/, $\mathrm{R}$ version 3.2.3, 2015-12-10), (Maechler et al. 2016).

\section{Results}

Forty-one children (22 boys and 19 girls, age range 4-13 years, mean age 6.8 years) suffering from 
chronic cough were included into the study. Based on outpatient examination by immunoallergologist patients were divided into subgroups of 17 atopy-negative ( 6 boys, 11 girls, mean age 6.9 years) and 24 atopypositive patients ( 16 boys, 8 girls, mean age 6.7 years).

BMI was calculated. Pulmonary function was within normal range. Concentrations of capsaicin causing two (C2) and five coughs (C5) were reported. Children' ( 22 boys and 19 girls, mean age 6.8 years) cough reflex sensitivity (median, with the Inter-Quartile Range) for C2 was 19.5 (73.4) $\mu \mathrm{mol} / \mathrm{l}$; for $\mathrm{C} 5$ it was 78.1 (605.5) $\mu \mathrm{mol} / 1$. There was not significant difference between obese and non-obese children in concentrations of capsaicin causing two (C2) coughs $(\mathrm{P}=0.7)$ and five coughs $(\mathrm{C} 5)(\mathrm{P}=0.3)$. There was no statistically significant difference between obese atopic children and non-obese atopic children for $\mathrm{C} 2$ value $(\mathrm{P}>0.9)$ and for $\mathrm{C} 5$ value $(\mathrm{P}=0.8)$.

But we have noticed statistically significant negative relation of the cough reflex sensitivity (C5) and body mass index $(\mathrm{P}<0.0001)$; however, the effect size was small, $R^{2}=0.03$. Increase of body mass index in one unit is associated with $-34.959 \mu \mathrm{mol} / 1$ decrease of C5 value (Fig. 1). We did not find a statistically significant relation between CKR $-\mathrm{C} 2$ value and BMI ( $\mathrm{P}=0.41)$.

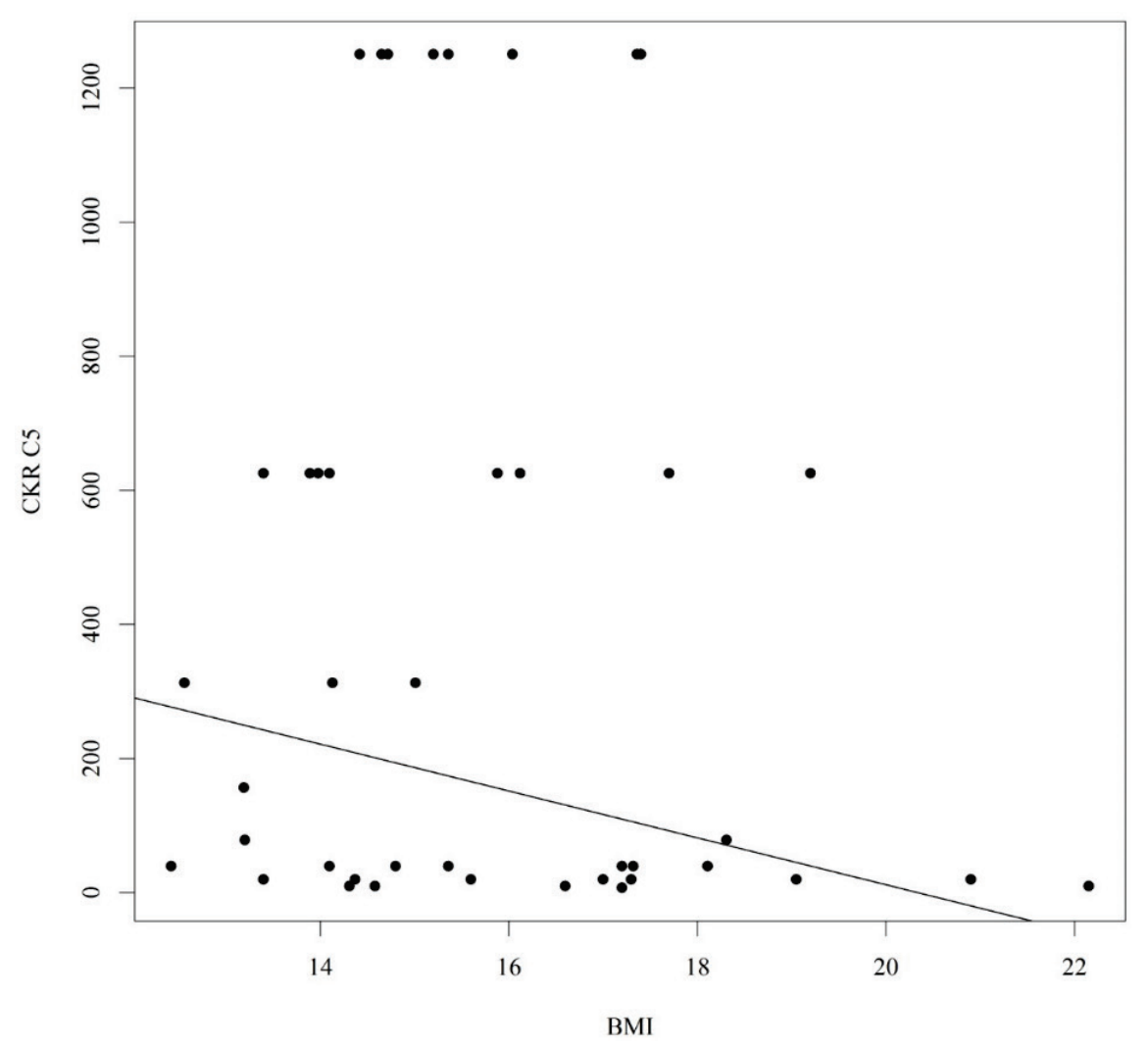

Fig. 1. Relationship between cough reflex sensitivity (CKR - C5 value) a BMI in children with chronic cough.

For the collection of 17 atopy-negative patients we did not find out statistically significant relation of the cough reflex sensitivity and BMI - $\mathrm{C} 2 \quad(\mathrm{P}=0.43)$, $\mathrm{C} 5(\mathrm{P}=0.66)$. For the collection of 24 atopy-positive patients we did not find out statistically significant relation of the cough reflex sensitivity and BMI $\mathrm{C} 2(\mathrm{P}=0.87), \mathrm{C} 5 \quad(\mathrm{P}=0.77)$. Immunoallergological status did not influence dependence between CRS and BMI.

In 17 atopy-negative children we found out 1 obese child and in 24 atopy-positive children we found out 1 obese and 8 overweight children (Table 1).
There is no statistically significant association between age composition and gender $(\mathrm{P}=0.7)$. The median value of CKR (C2) in boys is not statistically significantly different than the median value of CKR (C2) in girls ( $\mathrm{P}=0.5)$. The median value of CKR (C5) in boys is not statistically significantly different than the median value of $\mathrm{CKR}$ (C5) in girls ( $\mathrm{P}=0.5)$. With regard to the number of girls in the study group, there was a nonsignificant tendency to changes of the sensitivity of cough reflex in girls and boys. 
Table 1. Proportion of children with chronic cough in weight status categories.

\begin{tabular}{lccccc}
\hline $\begin{array}{l}\text { Alergological } \\
\text { status }\end{array}$ & Number & $\begin{array}{c}\text { Underweight } \\
\mathbf{( \% )}\end{array}$ & $\begin{array}{c}\text { Normal Weight } \\
\mathbf{( \% )}\end{array}$ & $\begin{array}{c}\text { Overweight } \\
\mathbf{( \% )}\end{array}$ & Obese (\%) \\
\hline $\begin{array}{l}\text { Negative and } \\
\text { positive }\end{array}$ & 41 & $4(9.8 \%)$ & $27(65.9 \%)$ & $8(19.5 \%)$ & $2(4.9 \%)$ \\
$\begin{array}{l}\text { Negative } \\
\text { Positive }\end{array}$ & 17 & $2(11.8 \%)$ & $14(82.4 \%)$ & $0(0 \%)$ & $1(5.9 \%)$ \\
\hline
\end{tabular}

\section{Discussion}

The aim of this study was to assess the relation of cough reflex sensitivity due to body mass index (BMI) in atopic and non-atopic children with chronic cough.

Chronic cough is a common entity in respiratory medicine. It is a complex disorder, the management of which has recently been defined in the guidelines of the European Respiratory Society (Morice et al. 2020). All the steps covering the investigations and initial treatments are detailed in these guidelines. However, body mass index measurement and assessment of obesity markers are not included in the evaluation of patients with chronic cough. Over the last years, obesity has increased worldwide and is now considered to be a genuine public health problem. Chronic cough places high demands on health care systems but it is not classically associated with obesity. In clinical practice, it is not surprising to observe the combination of two common diseases (Guilleminault et al. 2019). Chronic cough is reported by $10-20 \%$ of adults and this disorder is more common in female and obese subjects (Morice et al. 2006). Patients with a higher BMI experience cough more often than other patients and the cough is more severe in obese patients (Morales-Estrella et al. 2017). Haldar et al. (2008) found an obese asthma phenotype with noneosinophilic inflammation. The inflammatory profile of asthma may be different in obese patients compared to non-obese patients and the role of eosinophils in inflammation may be less crucial in obese asthmatics than non-obese asthmatics. However, sub-mucosal eosinophilic inflammation has also been found in asthma patients with obesity, which indicates that the association is probably more complex (Desai et al. 2013). In our study immunoallergological status did not influence dependence between CRS and BMI.

In recent decades, the worldwide prevalence of allergic disease has increased considerably (Aw et al. 2020). There has been a significant increase in the prevalence of asthma, atopy, and obesity in children worldwide (Woolcock and Peat 1997). It is possible that these events are linked (Gennuso et al. 1998, Huang et al. 1999, Shaheen et al. 1999). The association between asthma and obesity is well-described, but not straightforward, and according to current guidelines asthma control is more difficult to achieve in obese patients (Ulrik 2016a). In adults, large random population studies have shown an increase in the incidence and prevalence of wheezing and diagnosed asthma in obese subjects (Schachter et al. 2001). Weight reduction in obese adults with asthma leads to an overall improvement in asthma control, including airway hyperresponsiveness and inflammation. Weight reduction should be a cornerstone in the management of obese patients with asthma (Ulrik 2016b). In children two meta-analyses, published in 2013 and 2019, focused on the obese asthmatic phenotype and assessed the positive correlation between asthma and childhood obesity or overweight (Chen et al. 2013, Deng et al. 2019). The association between obesity and atopy has also rarely been explored. It is possible that obesity could cause atopy or inflammation or that there is some common factor that predisposes to both obesity and atopy (Schachter et al. 2001).

The relationships between atopy and obesity remain uncertain, both in adults and in children. Although there are physiopathologic mechanisms which could explain how obesity could influence the immune system and promote the process of sensitization, evidences in favor of a possible role of obesity on the development of atopy have been inconsistent. Furthermore, the bulk of evidence suggests that atopy does not mediate the relationship between obesity and asthma, although in some populations, particularly in children and women, such association has been reported (Boulet 2015).

In our study there was not significant difference between obese and non-obese children suffering from chronic cough and no statistically significant difference 
between obese atopic children and non-obese atopic children suffering from chronic cough. Due to the existence of subclinical inflammation, we assumed an increase in cough reflex sensitivity (C5) in obese children. This could be due to the size of the file and the fact that obesity was mild. There was no statistically significant difference in cough reflex sensitivity (CKR) between boys and girls with respect to age of children in our study (Varechova et al. 2008).

Limitations in this study that should be noted include the following: (1) Sampling. All cases were diagnosed with chronic cough, and there was no normal control group. (2) The unequal number of boys and girls and the sample size used in the study was rather small. Having a small sample size made the statistical results not as objective as they would be if a larger sample size had been used. (3) Direct measurement of body fat. In the future studies, these limitations should to be addressed.

\section{Conclusions}

We have confirmed in our pilot study that cough reflex sensitivity in children with chronic cough depends also from BMI. There is a statistically significant, though rather weak, negative correlation between BMI and cough reflex sensitivity and this dependence in our cohort was not influenced by atopy status. Although very little is known about relationship between chronic cough in children and obesity this observation is of interest and merits further investigation.

\section{Conflict of Interest}

There is no conflict of interest.

\section{Acknowledgements}

This work was supported by the project of Ministry of Health of the Slovak Republic - 2018/12-UKMT-8.

\section{References}

AW M, PENN J, GAUVREAU GM, LIMA H, SEHMI R: Atopic March: Collegium Internationale Allergologicum Update 2020. Int Arch Allergy Immunol 181: 1-10, 2020. https://doi.org/10.1159/000502958

BEUTHER DA, SUTHERLAND ER: Overweight, obesity, and incident asthma: a meta-analysis of prospective epidemiologic studies. Am J Respir Crit Care Med 175: 661-666, 2007. https://doi.org/10.1164/rccm.200611$1717 \mathrm{OC}$

BOULET LP: Obesity and atopy. Clin Exp Allergy 45: 75-86, 2015. https://doi.org/10.1111/cea.12435

CHANG AB, PHELAN PD, ROBERTSON CF, NEWMAN RG, SAWYER SM: Frequency and perception of cough severity. J Paediatr Child Health 37: 142-145, 2001. https://doi.org/10.1046/j.1440-1754.2001.00608.X

CHANG AB, OPPENHEIMER JJ, WEINBERGER M, GRANT CC, RUBIN BK, IRWIN RS; CHEST EXPERT COUGH PANEL: Etiologies of chronic cough in pediatric cohorts: CHEST guideline and expert panel report. Chest 152: 607-617, 2017. https://doi:10.1016/j.chest.2017.06.006

CHEN YC, DONG GH, LIN KC, LEE YL: Gender difference of childhood overweight and obesity in predicting the risk of incident asthma: a systematic review and meta-analysis. Obes Rev 14: 222-231, 2013. https://doi.org/10.1111/j.1467-789X.2012.01055.x

DENG X, MA J, YUAN Y, ZHANG Z, NIU W: Association between overweight or obesity and the risk for childhood asthma and wheeze: An updated meta-analysis on 18 articles and 73252 children. Pediatr Obes 14: e12532, 2019. https://doi.org/10.1111/ijpo.12532

DESAI D, NEWBY C, SYMON FA, HALDAR P, SHAH S, GUPTA S, BAFADHEL M, SINGAPURI A, SIDDIQUI S, WOODS J, HERATH A, ANDERSON IK, BRADDING P, GREEN R, KULKARNI N, PAVORD I, MARSHALL RP, SOUSA AR, MAY RD, WARDLAW AJ, BRIGHTLING CE: Elevated sputum interleukin-5 and submucosal eosinophilia in obese individuals with severe asthma. Am J Respir Crit Care Med 188: 657-663, 2013. https://doi.org/10.1164/rccm.201208-1470OC

GENNUSO J, EPSTEIN LH, PALUCH RA, CERNY F: The relationship between asthma and obesity in urban minority children and adolescents. Arch Pediatr Adolesc Med 152: 1197-1200, 1998. https://doi.org/10.1001/archpedi.152.12.1197

GUILLEMINAULT L: Chronic cough and obesity. Pulm Pharmacol Ther 55: 84-88, 2019. https://doi.org/10.1016/j.pupt.2019.01.009 
HALDAR P, PAVORD ID, SHAW DE, BERRY MA, THOMAS M, BRIGHTLING CE, WARDLAW AJ, GREEN RH: Cluster analysis and clinical asthma phenotypes. Am J Respir Crit Care Med 178: 218-224, 2008. https://doi.org/10.1164/rccm.200711-17540C

HUANG SL, SHIAO G, CHOU P: Association between body mass index and allergy in teenage girls in Taiwan. Clin Exp Allergy 29: 323-329, 1999. https://doi.org/10.1046/j.1365-2222.1999.00455.x

JOHANSSON SG, BIEBER T, DAHL R, FRIEDMANN PS, LANIER BQ, LOCKEY RF, MOTALA C, ORTEGA MARTELL JA, PLATTS-MILLS TA, RING J, THIEN F, VAN CAUWENBERGE P, WILLIAMS HC: Revised nomenclature for allergy for global use: Report of the Nomenclature Review Committee of the World Allergy Organization, October 2003. J Allergy Clin Immunol 113: 832-836, 2004. https://doi.org/10.1016/j.jaci.2003.12.591

KUCZMARSKI RJ, OGDEN CL, GUO SS, GRUMMER-STRAWN LM, FLEGAL KM, MEI Z, WEI R, CURTIN LR, ROCHE AF, JOHNSON CL: 2000 CDC Growth charts for the United States: methods and development. Vital Health Stat 11 246: 1-190, 2002.

MAECHLER M, ROUSSEEUW P, STRUYF A, HUBERT M, HORNIK K: Cluster: Cluster Analysis Basics and Extensions. R package version 2.0.5., 2016.

MOORE WC, MEYERS DA, WENZEL SE, TEAGUE WG, LI H, LI X, D'AGOSTINO R JR, CASTRO M, CURRAN-EVERETT D, FITZPATRICK AM, GASTON B, JARJOUR NN, SORKNESS R, CALHOUN WJ, CHUNG KF, COMHAIR SA, DWEIK RA, ISRAEL E, PETERS SP, BUSSE WW, ERZURUM SC, BLEECKER ER: Identification of asthma phenotypes using cluster analysis in the Severe Asthma Research Program. Am J Respir Crit Care Med 181: 315-323, 2010. https://doi.org/10.1164/rccm.200906-0896OC

MORALES-ESTRELLA JL, CIFTCI FD, TRICK WE, HINAMI K: Physical symptoms screening for cardiopulmonary complications of obesity using audio computer-assisted self-interviews. Qual Life Res 26: 2085-2092, 2017. https://doi.org/10.1007/s11136-017-1549-x

MORICE AH, MCGARVEY L, PAVORD I, BRITISH THORACIC SOCIETY COUGH GUIDELINE GROUP: Recommendations for the management of cough in adults. Thorax 61 (Suppl 1): i1-24, 2006. https://doi.org/10.1136/thx.2006.065144

MORICE AH, FONTANA GA, BELVISI MG, BIRRING SS, CHUNG KF, DICPINIGAITIS PV, KASTELIK JA, MCGARVEY LP, SMITH JA, TATAR M, WIDDICOMBE J, EUROPEAN RESPIRATORY SOCIETY (ERS): ERS guidelines on the assessment of cough. Eur Respir J 29: 1256-1276, 2007. https://doi.org/10.1183/09031936.00101006

MORICE AH, MILLQVIST E, BIEKSIENE K, BIRRING SS, DICPINIGAITIS P, DOMINGO RIBAS C, HILTON BOON M, KANTAR A, LAI K, MCGARVEY L, RIGAU D, SATIA I, SMITH J, SONG W-J, TONIA T, VAN DEN BERG JWK, VAN MANEN MJG, ZACHARASIEWICZ A: ERS guidelines on the diagnosis and treatment of chronic cough in adults and children. Eur Respir J 55: 1901136, 2020. https://doi.org/10.1183/13993003.01136-2019

PORSBJERG C, MENZIES-GOW A: Co-morbidities in severe asthma: Clinical impact and management. Respirology 22: 651-661, 2017. https://doi:10.1111/resp.13026

SCHACHTER LM, SALOME CM, PEAT JK, WOOLCOCK AJ. Obesity is a risk for asthma and wheeze but not airway hyperresponsiveness. Thorax 56: 4-8, 2001. https://doi.org/10.1136/thorax.56.1.4

SCHACHTER LM, PEAT JK, SALOME CM: Asthma and atopy in overweight children. Thorax 58: 1031-1035, 2003. https://doi.org/10.1136/thorax.58.12.1031

SHAHEEN SO, STERNE JA, MONTGOMERY SM, AZIMA H: Birth weight, body mass index and asthma in young adults. Thorax 54: 396-402, 1999. https://doi.org/10.1136/thx.54.5.396

ULRIK CS: Asthma symptoms in obese adults: The challenge of achieving asthma control. Expert Rev Clin Pharmacol 9: 5-8, 2016a. https://doi.org/10.1586/17512433.2016.1093415

ULRIK CS: Asthma and obesity: is weight reduction the key to achieve asthma control? Curr Opin Pulm Med 22: 69-73, 2016b. https://doi.org/10.1097/MCP.0000000000000226

VARECHOVA S, PLEVKOVA J, HANACEK J, TATAR M: Role of gender and pubertal stage on cough sensitivity in childhood and adolescence. J Physiol Pharmacol 59 (Suppl 6): 719-726, 2008. 
WEIHRAUCH-BLÜHER S, KROMEYER-HAUSCHILD K, GRAF C, WIDHALM K, KORSTEN-RECK U, JÖDICKE B, MARKERT J, MÜLLER MJ, MOSS A, WABITSCH M, WIEGAND S: Current guidelines for obesity prevention in childhood and adolescence. Obes Facts 11: 263-276, 2018. https://doi:10.1159/000486512

WOOLCOCK AJ, PEAT JK: Evidence for the increase in asthma worldwide. Ciba Found Symp 206: 122-159, 1997. https://doi.org/10.1002/9780470515334.ch8 